\title{
Hypophosphatemic rickets and craniosynostosis: a multicenter case series
}

\author{
Rafael A. Vega, MD, PhD, ${ }^{1}$ Charles Opalak, MD, MPH, ${ }^{1}$ Raymond J. Harshbarger, MD, ${ }^{3}$ \\ Jeffrey A. Fearon, MD, ${ }^{4}$ Ann M. Ritter, MD, ${ }^{1}$ John J. Collins, MD, ${ }^{1}$ and Jennifer L. Rhodes, MD² \\ Departments of ${ }^{1}$ Neurosurgery and ${ }^{2}$ Surgery, Division of Plastic and Reconstructive Surgery, Children's Hospital of Richmond, \\ Virginia Commonwealth University Health System, Richmond, Virginia; ${ }^{3}$ Craniofacial and Pediatric Plastic Surgery, Dell \\ Children's Medical Center of Central Texas, Austin, Texas; and 4The Craniofacial Center, Medical City Children's Hospital, Dallas, \\ Texas
}

OBJECTIVE This study examines a series of patients with hypophosphatemic rickets and craniosynostosis to characterize the clinical course and associated craniofacial anomalies.

METHODS A 20-year retrospective review identified patients with hypophosphatemic rickets and secondary craniosynostosis at 3 major craniofacial centers. Parameters examined included sex, age at diagnosis of head shape anomaly, affected sutures, etiology of rickets, presenting symptoms, number and type of surgical interventions, and associated diagnoses. A review of the literature was performed to optimize treatment recommendations.

RESULTS Ten patients were identified (8 males, 2 females). Age at presentation ranged from 1 to 9 years. The most commonly affected suture was the sagittal (6/10 patients). Etiologies included antacid-induced rickets, autosomal dominant hypophosphatemic rickets, and X-linked hypophosphatemic $(\mathrm{XLH})$ rickets. Nine patients had undergone at least 1 cranial vault remodeling (CVR) surgery. Three patients underwent subsequent surgeries in later years. Four patients underwent formal intracranial pressure (ICP) monitoring, 3 of which revealed elevated ICP. Three patients were diagnosed with a Chiari Type I malformation.

CONCLUSIONS Secondary craniosynostosis develops postnatally due to metabolic or mechanical factors. The most common metabolic cause is hypophosphatemic rickets, which has a variety of etiologies. Head shape changes occur later and with a more heterogeneous presentation compared with that of primary craniosynostosis. CVR may be required to prevent or relieve elevated ICP and abnormalities of the cranial vault. Children with hypophosphatemic rickets who develop head shape abnormalities should be promptly referred to a craniofacial specialist.

http://thejns.org/doi/abs/10.3171/2015.10.PEDS15273

KEY WORDS craniofacial surgery; craniosynostosis; hypophosphatemia; rickets

$\mathrm{C}$ RANIOSYNOSTOSIS may develop in utero or postnatally as a result of metabolic or mechanical factors. ${ }^{13}$ Most congenital forms of craniosynostosis present in infancy, while craniosynostosis due to metabolic causes more commonly presents around 2 years of age. Hypophosphatemic rickets is the most common metabolic cause of craniosynostosis. ${ }^{27}$

Rickets is a childhood disease in which new bone fails to mineralize. ${ }^{15}$ Rickets is characterized by a lack of vitamin D, which is responsible for maintaining adequate amounts of calcium and phosphorus in the bloodstream. ${ }^{18}$ Plasma calcium levels are abnormally low despite adequate intake of vitamin D and calcium in the hypophos- phatemic forms of rickets. Phosphate depletion may occur either from inadequate absorption or increased losses from either the kidney or the gastrointestinal tract. In developed countries, where poor vitamin D intake is rare, the prevalence of hypophosphatemic rickets is estimated at 1 in 20,000 people. $^{3}$

Hypophosphatemic rickets has been associated with synostosis of the coronal, lambdoid, and sagittal sutures, including pansynostosis, but is believed to most commonly affect the sagittal suture. ${ }^{3}$ Hypophosphatemic rickets was first described as a cause of craniosynostosis in 1951 by Imerslund. ${ }^{10}$ There remains a paucity of information on this subject in the medical literature.

ABBREVIATIONS CM = Chiari malformation; $\mathrm{CM}-\mathrm{I}=\mathrm{CM}$ Type I; CVR = cranial vault remodeling; FGF23 = fibroblast growth factor 23 ; ICP = intracranial pressure; XLH = X-linked hypophosphatemic.

SUBMITTED May 03, 2015. ACCEPTED October 07, 2015.

INCLUDE WHEN CITING Published online January 29, 2016; DOI: 10.3171/2015.10.PEDS15273. 
The purpose of this study was to retrospectively examine records of 10 patients with hypophosphatemic rickets and craniosynostosis to further characterize the presentation and clinical course and to identify associated craniofacial anomalies. A literature review was performed in an effort to optimize treatment recommendations.

\section{Methods}

This review was conducted as a multicenter study. After Institutional Review Board approval, the patient databases at 3 craniofacial centers (Children's Hospital of Richmond, Dell Children's Medical Center, and the Medical City Children's Hospital) were queried. Patients with the concurrent diagnoses of hypophosphatemia and craniosynostosis over the last 20 years were collected. A total of 10 patients were identified.

A review of the English-language literature was undertaken using PubMed with the key words "hypophosphatemic rickets" and "craniosynostosis." This produced 10 relevant papers, $3,7,8,11,17,19,24,25,27$ and these papers yielded 3 additional pertinent references of hypophosphatemic rickets linked with craniosynostosis., ${ }^{4,13,16}$ Relevant data extracted from these papers can be reviewed in Table 1.

\section{Case Series}

\section{Case 1}

Patient 1 presented at 18 months of age with a dolichocephalic skull shape and a diagnosis of X-linked hypophosphatemic (XLH) rickets. He was treated with calcitrol and oral phosphate replacement. Sagittal craniosynostosis was confirmed by CT imaging (Figs. 1 and 2). In the subsequent months, he began to experience headaches with increasing frequency. Head circumference was average for his age. Posterior cranial vault remodeling (CVR) was performed at 24 months of age. After 5 years of follow-up, he remains symptom free with a stable head shape.

\section{Case 2}

Patient 2 presented with pansynostosis in infancy and was diagnosed with antacid-induced hypophosphatemic rickets. Antacid therapy was prescribed to treat gastroesophageal reflux disease. Total calvarial vault remodeling was performed at 12 months of age. He re-presented at 18 years of age with brachycephaly, anterior turricephaly, and mild proptosis. At age 20, he underwent anterior CVR with posterior split skull cranioplasty and cranial bone graft reconstruction of his upper nasal dorsum. After a further 3 years of follow-up his reconstruction remains stable.

\section{Case 3}

Patient 3 presented at age 3 with an abnormal skull shape and frequent headaches as well as a diagnosis of familial hypophosphatemic rickets. This male child was treated transiently with calcitrol and calcium. On physical examination, brachycephaly was noted (Fig. 3). MRI revealed a significant Chiari malformation Type I (CM-I). $\mathrm{CT}$ imaging revealed pansynostosis. Intracranial pressure (ICP) monitoring revealed frankly elevated ICP (> $20 \mathrm{~mm}$
$\mathrm{Hg}$ ), and anterior CVR was performed (Fig. 4). After 3 years of follow-up, he remains without symptoms of raised ICP, his CM remains asymptomatic, and his head shape remains stable.

\section{Case 4}

Patient 4 is a 5-year-old boy with a diagnosis of XLH rickets who presented with sagittal synostosis, a decline in school performance, and headaches. He was treated with calcitrol and oral phosphate replacement. He underwent ICP monitoring that was found to be within the normal range. The patient has since been followed up without any acute intervention. He is being treated for migraines in the neurology department at Dell Children's Medical Center of Central Texas. He is meeting all milestones to date. The patient has been followed-up for 3 years.

\section{Case 5}

Patient 5 presented with scaphocephaly, papilledema, and frontal bossing at age 4 and had been diagnosed with hypophosphatemic rickets at 18 months of age. Medical management included phosphorus and vitamin D. CT imaging of the head showed sagittal craniosynostosis and a CM-I; ICP monitoring over 48 hours confirmed elevated pressures $(>20 \mathrm{~mm} \mathrm{Hg}$ ). Intervention was undertaken 3 months later, and the patient underwent CVR with rib grafting. Her condition remains improved at 2 years of follow-up.

\section{Case 6}

Patient 6 presented at 9 years of age with an unusual skull shape and a diagnosis of familial hypophosphatemic rickets. He was treated with calcitrol and oral phosphate replacement. ICP monitoring demonstrated increased ICP (> $20 \mathrm{~mm} \mathrm{Hg}$ ). Radiography noted pansynostosis as well as CM-I with syringomyelia. The patient was initially treated with direct Chiari decompression and anterior CVR 6 months later. He again developed increased ICP after 2 years of follow-up. The patient underwent posterior cranial vault distraction that resulted in normalization of ICP and improvement of syringomyelia after 1 year of additional follow-up.

\section{Case 7}

Patient 7 presented at 4 years of age with a prominent sagittal ridge and scaphocephaly. She was diagnosed in the perinatal period with XLH rickets investigated based on strong family history. She was treated with calcitrol and oral phosphate replacement. CT imaging confirmed sagittal craniosynostosis. The patient underwent CVR with rib grafting at 4 years of age. She has remained stable over the course of 2 years of follow-up.

\section{Case 8}

Patient 8 is a boy who was adopted shortly after birth. His adoptive mother noted bowed legs at age 1.5 years. A fall at age 2 led to a hospital admission, at which time the diagnosis of rickets was made. Genetic evaluation confirmed XLH rickets. Therapy with calcitrol and oral 


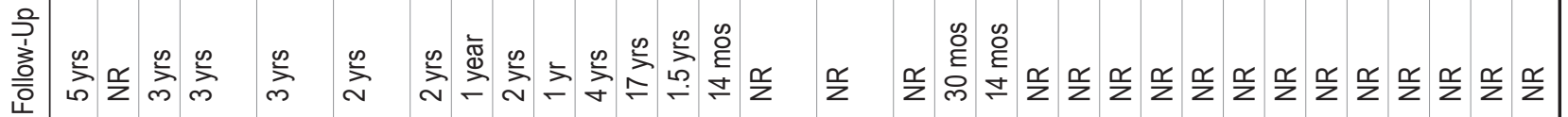

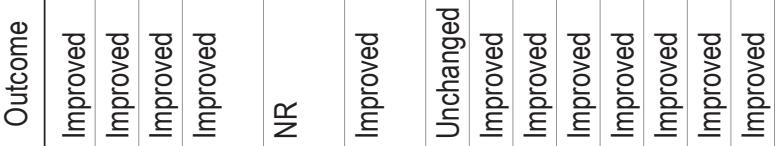

章 总

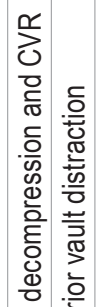

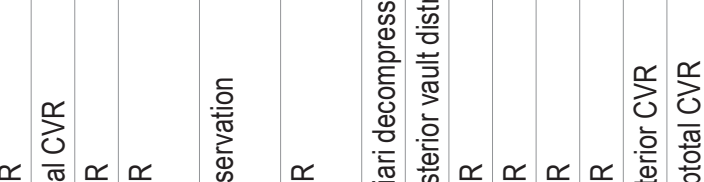

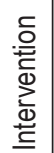

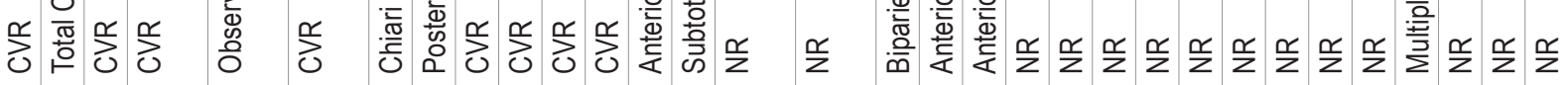

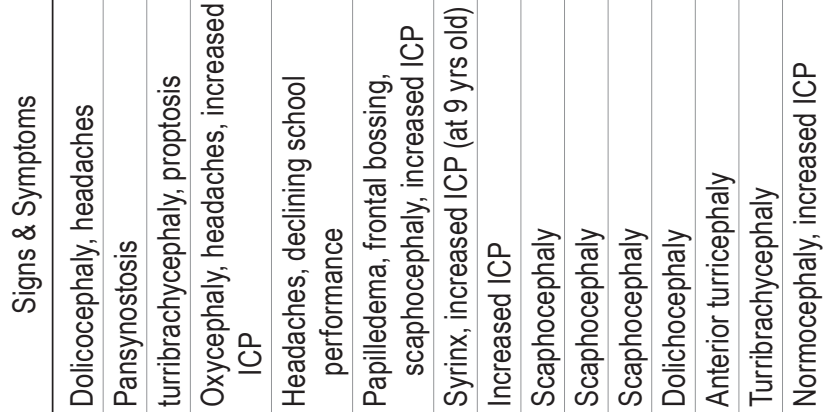

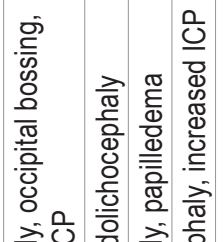

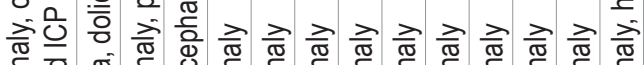

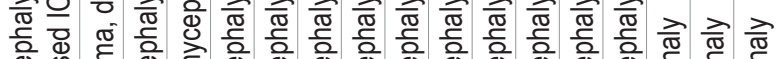
边

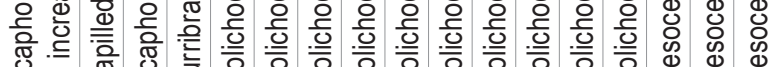

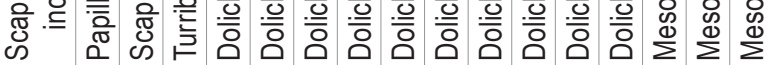

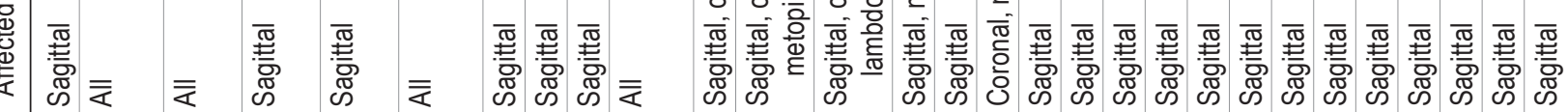

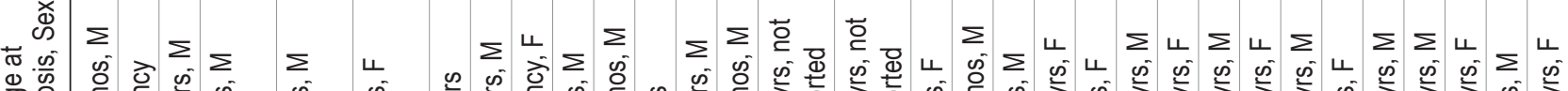

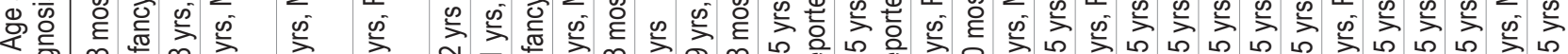

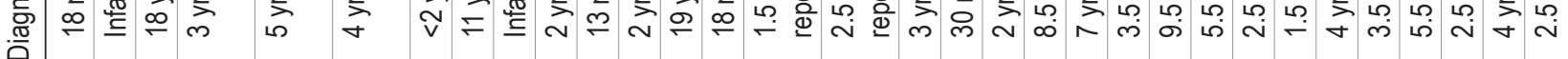

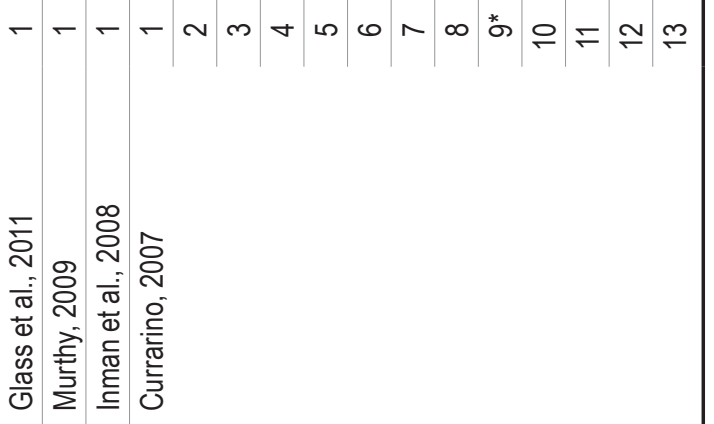

i

产

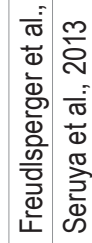

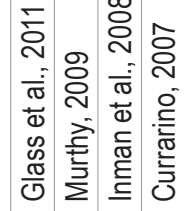



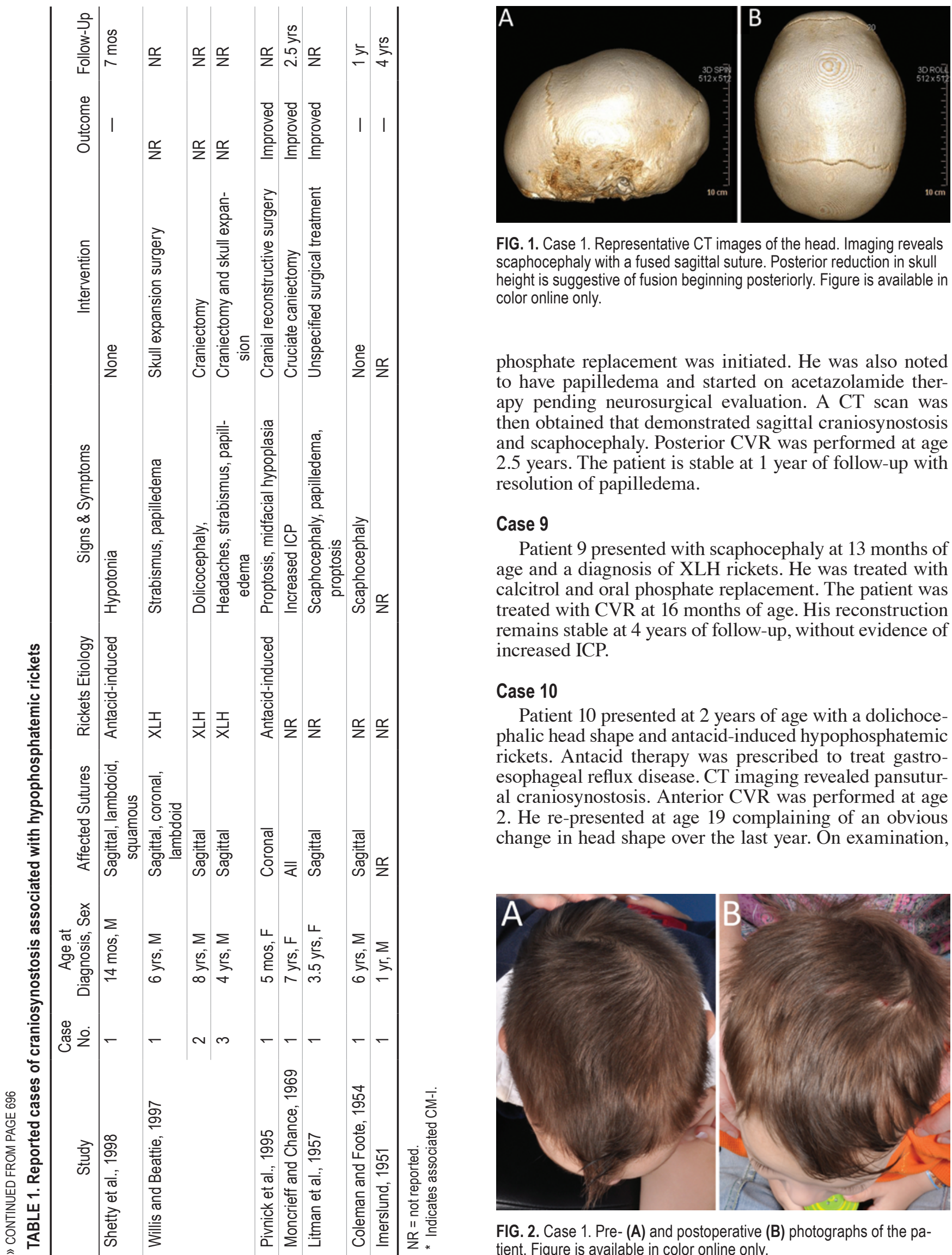

FIG. 1. Case 1. Representative CT images of the head. Imaging reveals scaphocephaly with a fused sagittal suture. Posterior reduction in skull height is suggestive of fusion beginning posteriorly. Figure is available in color online only.

phosphate replacement was initiated. He was also noted to have papilledema and started on acetazolamide therapy pending neurosurgical evaluation. A CT scan was then obtained that demonstrated sagittal craniosynostosis and scaphocephaly. Posterior CVR was performed at age 2.5 years. The patient is stable at 1 year of follow-up with resolution of papilledema.

\section{Case 9}

Patient 9 presented with scaphocephaly at 13 months of age and a diagnosis of XLH rickets. He was treated with calcitrol and oral phosphate replacement. The patient was treated with CVR at 16 months of age. His reconstruction remains stable at 4 years of follow-up, without evidence of increased ICP.

\section{Case 10}

Patient 10 presented at 2 years of age with a dolichocephalic head shape and antacid-induced hypophosphatemic rickets. Antacid therapy was prescribed to treat gastroesophageal reflux disease. CT imaging revealed pansutural craniosynostosis. Anterior CVR was performed at age 2. He re-presented at age 19 complaining of an obvious change in head shape over the last year. On examination,

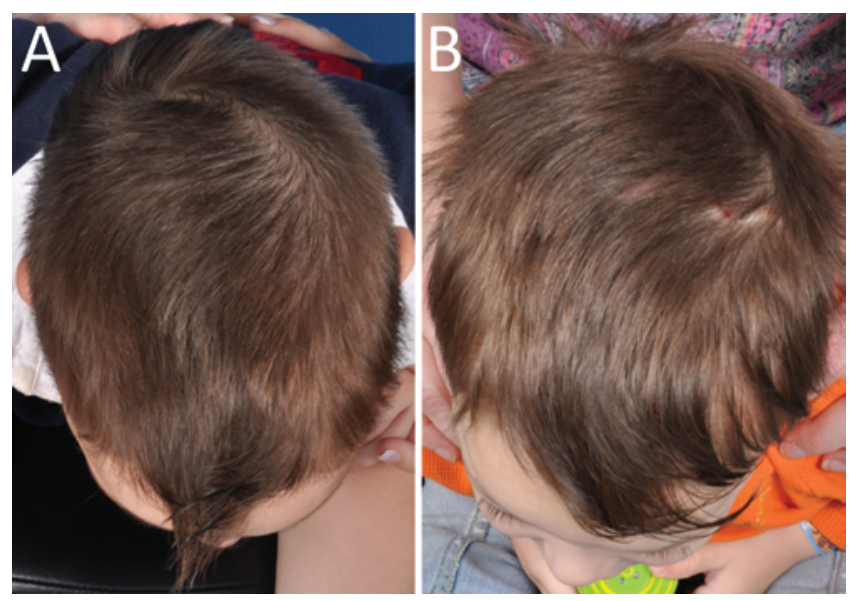

FIG. 2. Case 1. Pre- (A) and postoperative (B) photographs of the patient. Figure is available in color online only. 

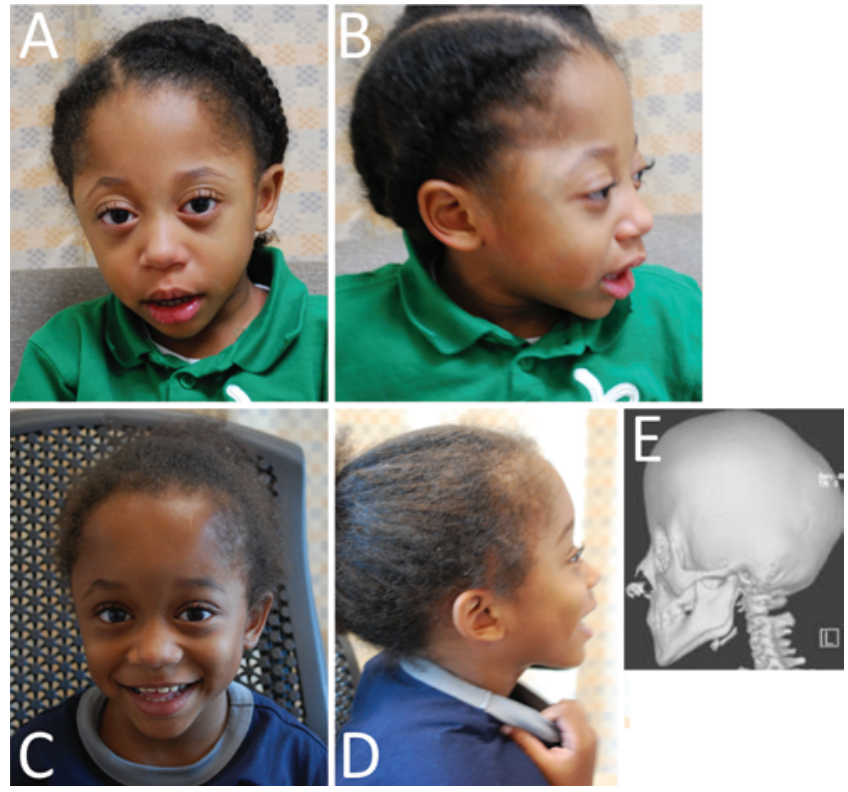

FIG. 3. Case 3. Pre- (A and B) and postoperative (C and D) photographs and preoperative CT scan (E). Imaging revealed fusion of both coronal and lambdoid sutures. Figure is available in color online only.

anterior turricephaly was noted. Anterior CVR was performed, and the patient is stable at 1.5 years of follow-up.

\section{Results}

Ten patients were identified, including 8 males and 2 females (Table 1). Age at initial presentation for craniofacial evaluation ranged from 1 to 9 years, with a mean age of 25 months. Nine of the 10 patients in our series have undergone CVR surgery. Three required a second CVR surgery. The 2 patients in our series with antacid-induced hypophosphatemic rickets both required a second CVR procedure at skeletal maturity after the development of obvious skull shape changes. The most common presentation was isolated sagittal synostosis in 6 of the 10 patients. Pansynostosis was noted in 4 of the 10 patients.

Etiologies encountered in our case series included antacid-induced hypophosphatemic rickets and genetic forms of hypophosphatemic rickets, most commonly Xlinked. Four patients underwent formal ICP monitoring, 3 of which revealed elevated ICP. Three patients were diagnosed with a CM, one of whom required direct Chiari decompression in addition to a CVR procedure.

\section{Discussion}

Hypophosphatemic rickets may have a variety of etiologies. The normal physiologic response to hypophosphatemia is an elevation in vitamin D; however, this does not occur in hypophosphatemic rickets. Patients typically have an unremarkable perinatal course, but begin to manifest particular features, such as short stature, osteomalacia, and genu varum, within the first 2 years of life. Low serum and high urine phosphate levels along with unusually normal levels of vitamin $\mathrm{D}$ are diagnostic.

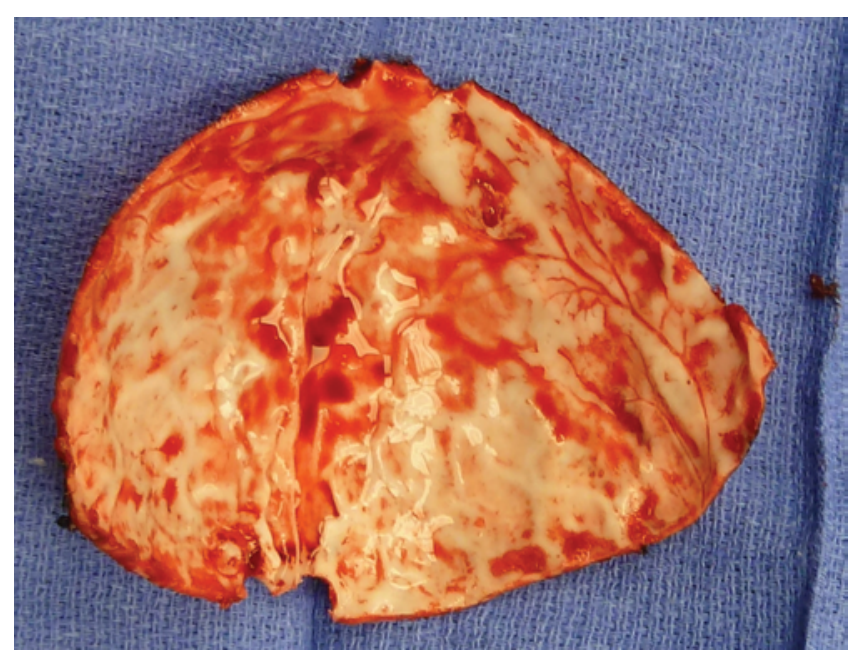

FIG. 4. Case 3. Intraoperative findings demonstrate the inner cortex of the frontal bone. A gross specimen revealed thickened bone with evidence of thumb printing. Figure is available in color online only.

XLH rickets is the most common subtype and typically presents in children around 2 years of life. ${ }^{2}$ The etiology underlying this association has yet to be fully elucidated. However, it is presumed to be due to the downstream alteration in bone metabolism that results from the dysregulation of phosphate and vitamin D metabolism through influence of the loss-of-function mutations of the PHEX gene on fibroblast growth factor 23 (FGF23). ${ }^{6,9,12,20,26}$ These dominant loss of function mutations in the PHEX gene are found in $80 \%$ of cases of XLH rickets. ${ }^{22}$ FGF23 is produced and secreted by osteoblastic osteocytes in bone, and excessive FGF23 production can be associated with hypophosphatemia through its influence on renal tubules. Literature reviews also suggest that at high levels, FGF23 can cross-bind with FGF receptors 2 and 3 at the cranial sutures. ${ }^{17}$ Mutations of these two FGF receptors have welldocumented associations with several syndromic forms of craniosynostosis; such cross-binding by elevated FGF23 may play a role in the association between XLH and craniosynostosis.

Autosomal dominant and autosomal recessive forms of hypophosphatemic rickets are less commonly seen. No cure exists for these genetic causes of hypophosphatemic rickets, but early treatment with calcitriol and oral phosphate supplements significantly improves outcomes.

Antacid-induced hypophosphatemic rickets is another important etiology associated with craniosynostosis. Oral antacids are occasionally prescribed for infantile colic, gastroesophageal reflux, esophagitis, and other peptic disorders. Prolonged treatment with aluminum-magnesium hydroxides in particular can limit renal tubular resorption and gastrointestinal absorption of phosphorus, leading to severe depletion. ${ }^{3}$ In addition, soy-based formulas, which contain phytates, may impair absorption of minerals, including calcium, phosphate, iron, and zinc, ${ }^{5}$ which exacerbates the problem because their use is often coincident with antacids in infants with colic. At this time, it is recommended to use aluminum-containing antacid therapy cautiously and in low doses with routine monitoring of 
serum calcium and phosphorous if prolonged therapy is indicated.

The true incidence of craniosynostosis in hypophosphatemic rickets remains poorly characterized, ranging from $12 \%$ to $46 \% .3,21,27$ The sagittal suture is the most commonly affected in 6 of 10 in our series, which correlates with the compiled data in the literature (23/28 cases). Greater age at initial presentation for hypophosphatemic rickets and milder symptomatology are correlated with a lower incidence and severity of craniosynostosis. ${ }^{21}$

There is a marked male predominance in our case series $(8 / 10)$, which is more than reported in the literature $(15 / 28)$. Willis and Beattie postulated that this sex disparity was due either to a more severe phenotype being expressed in males with XLH-dependent rickets or to a more aggressive treatment provoked by a severe phenotype. ${ }^{27}$ Of the cases in which X-linked hypophosphatemic rickets was the confirmed diagnosis, $12 / 22$ patients were male, $8 / 22$ were female, and in $2 / 22$ sex was not reported. This male predominance of craniosynostosis exists despite the higher prevalence of XLH rickets in females.

In mouse models with X-linked dominant hypophosphatemia, ${ }^{23}$ synostosis was present in the sagittal, metopic, and midpalatal sutures but not in the transversely oriented coronal, lambdoid, or frontonasal sutures. This finding has not been upheld in the case studies reviewed in the literature, with 7 of the 38 compiled cases having transverse suture synostosis.

CM-I has been reported to be associated with craniosynostosis. Caldemeyer et al. reported 7 patients with CM-I in a series of 16 patients with hereditary hypophosphatemic rickets. ${ }^{1}$ This associated diagnosis was also observed in another case from the literature ${ }^{3}$ in addition to 3 cases presented in our series. Caldemeyer observed that this may be due to the thickening of the calvaria and flattening of the posterior fossa, and the comorbidity may be much higher than reported in the literature, because CMs are often asymptomatic and only found incidentally in this setting. ${ }^{1}$

The authors' review of the literature allows emphasis of situations when clinical suspicion of hypophosphatemic rickets and craniosynostosis should be elevated. In particular, this should be the case when children less than 10 years of age present with an unusual head shape or finding concerning for elevated ICP, such as frequent headaches, papilledema, or strabismus. A careful medical and family history as well as a history of medication usage should also be obtained. ${ }^{25}$ High clinical suspicion is also necessary in children with these symptoms because, unlike nonsyndromic craniosynostosis ${ }^{13}$ or craniosynostosis associated with Apert or another syndromic disease, hypophosphatemic rickets-induced craniosynostosis typically presents at a later age, because it is not usually present perinatally. Additionally, the physical examination may be less specific in these cases than in congenital craniosynostosis due to a wide variety of skull shape presentations, including normocephaly. ${ }^{23,27}$

Limitations of our study include the retrospective nature of the review and follow-up period, which ranged from 1 to 5 years postoperatively. This is most apparent when the progressive and recurrent nature of synostosis in hypophosphatemic rickets is discussed. In 2 of our cases, there was a redevelopment ( $>10$ years) of significant cranial abnormalities that required a second surgical correction. Of note, both patients had an etiology similar to that of antacid-induced rickets. However, at this time, it is unclear if this progressive and recurrent phenomenon can occur long term in the other patients identified in this study.

\section{Conclusions}

Cases of craniosynostosis that present after infancy should include hypophosphatemic rickets in the differential diagnosis. A careful physical examination may reveal additional findings indicative of rickets, including bowing of the legs, short stature, and a rachitic rosary. The authors of this study recommend that providers caring for children with hypophosphatemic rickets screen their patients for signs and symptoms of increased ICP and changes in the head shape at each visit. Any findings should prompt a referral to a craniofacial specialist for further evaluation, including $\mathrm{CT}$ of the cranium and screening for papilledema. Treatment is primarily surgical, with good results with CVR having been obtained in the current case series.

\section{References}

1. Caldemeyer KS, Boaz JC, Wappner RS, Moran CC, Smith RR, Quets JP: Chiari I malformation: association with hypophosphatemic rickets and MR imaging appearance. Radiology 195:733-738, 1995

2. Carpenter TO: New perspectives on the biology and treatment of X-linked hypophosphatemic rickets. Pediatr Clin North Am 44:443-466, 1997

3. Currarino G: Sagittal synostosis in X-linked hypophosphatemic rickets and related diseases. Pediatr Radiol 37:805812,2007

4. Coleman EN, Foote JB: Craniostenosis with familial vitamin-D-resistant rickets. BMJ 1:561-562, 1954

5. Erdman JW, Forbes RM: Effects of soya protein on mineral availability. J Am Oil Chem Soc 58:489-495, 1989

6. Fearon JA, Singh DJ, Beals SP, Yu JC: The diagnosis and treatment of single-sutural synostoses: are computed tomographic scans necessary? Plast Reconstr Surg 120:13271331, 2007

7. Freudlsperger C, Hoffmann J, Castrillon-Oberndorfer G, Engel M: Bilateral coronal and sagittal synostosis in X-linked hypophosphatemic rickets: a case report. J Craniomaxillofac Surg 41:842-844, 2013

8. Glass LRD, Dagi TF, Dagi LR: Papilledema in the setting of $\mathrm{X}$-linked hypophosphatemic rickets with craniosynostosis. Case Rep Ophthalmol 2:376-381, 2011

9. HYP Consortium: A gene (PEX) with homologies to endopeptidases is mutated in patients with X-linked hypophosphatemic rickets. Nat Genet 11:130-136, 1995

10. Imerslund O: Craniostenosis and vitamin $\mathrm{D}$ resistant rickets. Acta Paediatr 40:449-456, 1951

11. Inman PC, Mukundan S Jr, Fuchs HE, Marcus JR: Craniosynostosis and rickets. Plast Reconstr Surg 121:217e-218e, 2008

12. Jonsson KB, Zahradnik R, Larsson T, White KE, Sugimoto $\mathrm{T}$, Imanishi $\mathrm{Y}$, et al: Fibroblast growth factor 23 in oncogenic osteomalacia and X-linked hypophosphatemia. N Engl J Med 348:1656-1663, 2003

13. Kabbani H, Raghuveer TS: Craniosynostosis. Am Fam Physician 69:2863-2870, 2004

14. Litman NN, Ulstrom RA, Westin WW: Vitamin D resistant rickets. Calif Med 86:248-253, 1957 
15. McCarthy JG, Reid CA: Craniofacial synostosis in association with vitamin D-resistant rickets. Ann Plast Surg 4:149153,1980

16. Moncrieff MW, Chance GW: Nephrotoxic effect of vitamin D therapy in vitamin D refractory rickets. Arch Dis Child 44:571-579, 1969

17. Murthy AS: X-linked hypophosphatemic rickets and craniosynostosis. J Craniofac Surg 20:439-442, 2009

18. Pettifor JM: What's new in hypophosphataemic rickets? Eur J Pediatr 167:493-499, 2008

19. Pivnick EK, Kerr NC, Kaufman RA, Jones DP, Chesney RW: Rickets secondary to phosphate depletion. A sequela of antacid use in infancy. Clin Pediatr (Phila) 34:73-78, 1995

20. Quarles LD: FGF23, PHEX, and MEPE regulation of phosphate homeostasis and skeletal mineralization. Am J Physiol Endocrinol Metab 285:E1-E9, 2003

21. Reilly BJ, Leeming JM, Fraser D: Craniosynostosis in the rachitic spectrum. J Pediatr 64:396-405, 1964

22. Roth KS, Ward RJ, Chan JCM, Sarafoglou K: Disorders of calcium, phosphate and bone metabolism, in Sarafoglou K, Hoffmann GF, Roth KS (ed): Pediatric Endocrinology and Inborn Errors of Metabolism. New York: McGraw-Hill, 2009, pp 619-664

23. Roy WA, Iorio RJ, Meyer GA: Craniosynostosis in vitamin D-resistant rickets. A mouse model. J Neurosurg 55:265271,1981

24. Seruya M, Oh AK, Boyajian MJ, Myseros JS, Yaun AL, Keating RF, et al: Age at initial consultation for craniosynostosis: comparison across different patient characteristics. J Craniofac Surg 24:96-98, 2013

25. Shetty AK, Thomas T, Rao J, Vargas A: Rickets and second- ary craniosynostosis associated with long-term antacid use in an infant. Arch Pediatr Adolesc Med 152:1243-1245, 1998

26. Shimada T, Hasegawa H, Yamazaki Y, Muto T, Hino R, Takeuchi Y, et al: FGF-23 is a potent regulator of vitamin D metabolism and phosphate homeostasis. J Bone Miner Res 19:429-435, 2004

27. Willis FR, Beattie TJ: Craniosynostosis in X-linked hypophosphataemic rickets. J Paediatr Child Health 33:78-79, 1997

\section{Disclosures}

The authors report no conflict of interest concerning the materials or methods used in this study or the findings specified in this paper.

\section{Author Contributions}

Conception and design: Rhodes. Acquisition of data: Rhodes, Vega, Harshbarger, Fearon, Ritter, Collins. Analysis and interpretation of data: all authors. Drafting the article: Rhodes, Vega, Opalak. Critically revising the article: all authors. Reviewed submitted version of manuscript: all authors. Study supervision: Rhodes.

\section{Correspondence}

Jennifer L. Rhodes, Center for Craniofacial Care, Children's Hospital of Richmond, Virginia Commonwealth University Health System, Medical College of Virginia, P.O. Box 980154, Richmond,VA 23298-0154. email: jrhodes@mcvh-vcu.edu. 